\title{
VALOR NUTRITIVO DO RESÍDUO DE PRÓPOLIS PARA FRANGOS DE CORTE ${ }^{1}$
}

\begin{abstract}
RESUMO - Dois experimentos foram conduzidos no Setor de Avicultura do Departamento de Zootecnia da Universidade Federal de Lavras, com o objetivo de determinar o valor nutritivo do resíduo da própolis para a alimentação de frangos de corte. No primeiro experimento, determinou-se a energia metabolizável do resíduo da própolis, utilizando o método de coleta total de excretas, segundo metodologia de Sibbald e Slinger (1963), utilizando 16 galos adultos com peso médio de $2500 \pm 100 \mathrm{~g}$, alojados em gaiolas de metabolismo. Foram utilizadas duas rações com oito repetições de uma ave. As duas rações foram: (1) ração-referência à base de milho e farelo de soja e (2) $80 \%$ da ração-referência mais $20 \%$ do resíduo da extração da própolis. O valor de energia metabolizável aparente foi de $941 \mathrm{Kcal}$ de $\mathrm{EM} / \mathrm{kg}$ de MS. Ainda foram encontrados, no resíduo, $19,76 \%$ de proteína bruta, $26,76 \%$ de extrato etéreo e $14,41 \%$ de fibra bruta. Na fase de 1 a 21 dias de idade, para a variável consumo de ração, não houve efeito significativo para níveis de resíduo e para a interação níveis $x$ sexos $(P>0,05)$; no entanto, houve efeito significativo somente para sexos $(\mathrm{P}<0,01)$; o ganho de peso foi significativo para níveis e para sexos $(\mathrm{P}<0,01)$ e não
\end{abstract}

\author{
ASDRUBAL VIANA DOS SANTOS
ANTÔNIO SOARES TEIXEIRA \\ ASDRUBAL VIANA DOS SANTOS
ANTÔNIO SOARES TEIXEIRA \\ PAULO BORGES RODRIGUES
TADEU FONSECA DE FREITAS
TA \\ PAULO BORGES RODRIGUES
RILKE TADEU FONSECA DE FREITAS $^{5}$ \\ ANTÔNIO MARCOS GUIMARÃES ${ }^{6}$ \\ RENATO ALBERTO GIACOMETTI ${ }^{7}$
}

\begin{abstract}
houve interação entre níveis $x$ sexos $(P>0,05)$. Houve aumento no ganho de peso com nível de inclusão de até 2,86\% (LRP) de resíduo na ração para ambos os sexos, observando-se ainda que, nesse período, a adição do resíduo da própolis proporcionou piora na conversão alimentar para machos e fêmeas. Na fase de 1 a 42 dias para consumo de ração, houve efeito significativo para sexos $(\mathrm{P}<0,01)$ e para a interação níveis $\mathrm{x}$ sexos $(\mathrm{P}<0,05)$; porém, não houve efeito para os níveis de resíduo $(\mathrm{P}>0,05)$. Houve efeito significativo somente para os machos $(\mathrm{P}<0,05)$ que apresentaram um consumo máximo de 4,93\% (LRP) de inclusão do resíduo na ração. O ganho de peso para machos e fêmeas nessa fase decresceu linearmente e também aumentou de forma linear para conversão alimentar em ambos os sexos, com a adição do resíduo na ração. O uso do resíduo de própolis até $2,86 \%$ na ração aumentou o ganho de peso na fase de 1 a 21 dias e, na fase de 1 a 42 dias, o uso do resíduo da própolis na alimentação de frangos de corte reduziu o ganho de peso e piorou a conversão alimentar dos frangos de corte de 1 a 42 dias. Isso ocorreu provavelmente devido ao teor de fibra presente no resíduo $(14,41 \%)$ e ceras $(26,76 \%)$.
\end{abstract}

TERMOS PARA INDEXAÇÃO: Frango de corte, nutrição de monogástrico, resíduo de própolis.

\section{NUTRITIVE VALUE OF PROPOLLIS RESIDUE FOR BROILER CHIKENS}

\author{
ABSTRACT - Two experiments were run at the \\ Federal University of Lavras (Brazil) with the objective \\ Poultry Sector of the Animal Science Department of the \\ of determining the nutritive value of propollis residue \footnotetext{
Lavras, MG, pelo primeiro autor, para obtenção do título de Mestre em Zootecnia, na área Nutrição de Monogástricos.

2. Professor da Escola Agrotécnica Federal de Santa Inês - BA, 45320-000.

3. Professor do Departamento de Zootecnia/UFLA.

4. Professor do Departamento de Zootecnia/UFLA.

5. Professor do Departamento de Zootecnia/UFLA.

6. Professor do Departamento de Medicina Veterinária/UFLA.

7. Mestre em Zootecnia/UFLA.
} \\ 1. Parte da dissertação apresentada à UNIVERSIDADE FEDERAL DE LAVRAS/UFLA - Caixa Postal 37 - 37200-000 -
}


for broiler feeding. In the first experiment, the metabolizable energy of propollis residue was determined. In this experiment, 16 adults fed with $2,500 \pm 100 \mathrm{~g}$ of propollis were housed in a metabolism cage (Sibbald and Slinger, 1963). Two rations with eight replicates, one bird each, after an adaptation period of three day period and feces collection for five days were utilized. The two rations were (i) reference ration based on corn and soybean meal and (ii) $80 \%$ of the reference ration plus $20 \%$ of the propollis extraction residue. The value of apparent metabolizable energy was $941 \mathrm{kcal} / \mathrm{kg} \mathrm{DM}$. In addition, we found $20 \%$ crude protein, $27 \%$ ether extract, and $14 \%$ raw fiber. In the second experiment, the bird performance was evaluated by using five diets with $0,3,6,9$, and $12 \%$ of propollis extraction residue in a completely randomized performance design. The rations were isonutritive, with four replicates of males and four females, with 30 birds each, amounting to 1.200 birds, reared in $2 \times 1.5-\mathrm{m}$ boxes in a stonework house. In the first phase, 1 to 21 days, for the variable ration intake, there were no significant effects for residue levels and for level $\times$ gender interaction $(\mathrm{P}>0.05)$. Nevertheless, there was a significant effect only for gender $(\mathrm{P}<0.01)$ and there was no interaction between levels and gender ( $P$ $<0.05)$. Weight gain worsened linearly when the residue levels in the ration were raised for both males and females, observing that in this period the addition of residue provided a growing linear feed conversion for males and females. In phase 1 to 42 days, for ration intake, there was a significant effect for gender $(\mathrm{P}<0.01)$ and for level $\times$ gender interaction $(\mathrm{P}<0.05)$, but there was no significant difference among females $(\mathrm{P}<0.05)$. There was a significant effect only for males $(\mathrm{P}<0.05)$ which presented a maximum consumption of $5 \%$ of inclusion of residue in the ration. Weight gain of males and females in this phase decreased linearly and also increased in linear form for feed conversion in both genders with the addition of the residue in the ration. The use of propollis residue up to $3 \%$ in the ration increased weight gain in phase 1 to 21 days. But in broiler feeding from 1 to 42 days reduced the weight gain, worsened feed conversion and increased ration intake.

INDEX TERMS: Broiler chicken, nutrititon of monogastric, propollis residue.

\section{INTRODUÇÃO}

A apicultura tem se desenvolvido bastante nas últimas décadas, não somente visando à produção de mel, mas também à produção de própolis, pólen e geléia real.

A demanda crescente por própolis, tanto no mercado externo como interno, tem motivado os apicultores a diversificarem suas atividades. A própolis possui várias propriedades biológicas, sendo utilizada na medicina popular desde 300 a.C. Porém, somente nos últimos anos têm havido maiores interesses em estudar sua composição química, relacionando-a às atividades farmacológicas (MARCUCCI, 1996).

O extrato é cerca de $10 \%$ da própolis, e estima-se em 80 toneladas os resíduos que poderão estar disponíveis para a alimentação animal. A aplicação e utilização desses resíduos na alimentação animal poderá contribuir para a diminuição do desperdício e da poluição ambiental, o que atualmente tem sido motivo de preocupação mundial, além de fornecer nutrientes a baixo custo para reduzir os custos de produção. Assim, foi conduzido este trabalho com os seguintes objetivos: 1) Determinar a energia metabolizável aparente e a composição nutritiva parcial do resíduo da extração da própolis; 2) Avaliar o desempenho de frangos de corte alimentados com rações contendo diferentes níveis do resíduo da extração da própolis.

\section{MATERIAL E MÉTODOS}

O primeiro experimento foi realizado para determinar a energia metabolizável aparente do resíduo de própolis pelo método de coleta total de excretas, segundo metodologia de Sibbald e Slinger (1963), com inclusão de $20 \%$ do resíduo de própolis em uma dieta referência. Foram utilizados 16 galos adultos com dez meses de idade e peso médio de $2500 \pm 100 \mathrm{~g}$. Em uma sala de metabolismo com temperatura controlada a $22 \pm 1^{\circ} \mathrm{C}$, os galos foram alojados em um conjunto de baterias metálicas, com dois andares e oito gaiolas por andar, medindo $0,50 \mathrm{~m} \times 0,50 \mathrm{~m}$ x $0,50 \mathrm{~m}$ cada uma, totalizando 16 gaiolas. Cada gaiola possuía uma ave, um comedouro e um bebedouro tipo calha.

O segundo experimento foi realizado para avaliar o desempenho das aves, utilizando-se o delineamento experimental inteiramente ao acaso e cinco dietas (com 0, 3, 6, 9 e 12\% do resíduo da extração da própolis); as rações foram isonutritivas segundo recomendações de Rostagno et al. (2000) (Tabelas 1 e 2), com quatro repetições de machos e quatro de fêmeas, com 30 aves cada uma, num total de 1200 aves da linhagem Cobb, vacinados contra Marek e peso médio inicial de $42 \mathrm{~g}$ e criados em boxes com 2,0 x 1,5 m em galpão de alvenaria. 
TABELA 1 - Composição das rações utilizadas na fase inicial (1 a 21 dias) no experimento 2.

\begin{tabular}{|c|c|c|c|c|c|}
\hline \multirow{2}{*}{ Ingredientes } & \multicolumn{5}{|c|}{ Resíduo de Própolis (\%) } \\
\hline & Basal & 3 & 6 & 9 & 12 \\
\hline Milho & 57,66 & 54,92 & 50,83 & 46,73 & 42,64 \\
\hline Farelo de soja & 36,53 & 35,49 & 35,30 & 35,11 & 34,92 \\
\hline Óleo de soja & 1,98 & 2,85 & 4,14 & 5,43 & 6,72 \\
\hline Resíduo própolis & --- & 3,00 & 6,00 & 9,00 & 12,00 \\
\hline Fosfato bicálcico & 1,86 & 1,83 & 1,85 & 1,87 & 1,89 \\
\hline Calcário & 1,08 & 1,00 & 0,96 & 0,92 & 0,88 \\
\hline Sal & 0,46 & 0,40 & 0,40 & 0,41 & 0,41 \\
\hline Colina & 0,07 & 0,07 & 0,07 & 0,07 & 0,07 \\
\hline DL-metionina & 0,16 & 0,24 & 0,25 & 0,26 & 0,27 \\
\hline Suplemento mineral $^{1}$ & 0,05 & 0,05 & 0,05 & 0,05 & 0,05 \\
\hline Suplemento vitamínico ${ }^{2}$ & 0,05 & 0,05 & 0,05 & 0,05 & 0,05 \\
\hline Avilamicina $^{3}$ & 0,05 & 0,05 & 0,05 & 0,05 & 0,05 \\
\hline Salinomicina ${ }^{4}$ & 0,05 & 0,05 & 0,05 & 0,05 & 0,05 \\
\hline TOTAL & 100,00 & 100,00 & 100,00 & 100,00 & 100,00 \\
\hline \multicolumn{6}{|c|}{ Composição Nutritiva } \\
\hline EM (Kcal/kg) & 2950 & 2950 & 2950 & 2950 & 2950 \\
\hline Proteína bruta (\%) & 21,50 & 21,50 & 21,50 & 21,50 & 21,50 \\
\hline Metionina + cistina (\%) & 0,900 & 0,900 & 0,900 & 0,900 & 0,900 \\
\hline Lisina $(\%)$ & 1,140 & 1,140 & 1,140 & 1,140 & 1,140 \\
\hline Fósforo disponível (\%) & 0,450 & 0,450 & 0,450 & 0,450 & 0,450 \\
\hline Cálcio (\%) & 0,980 & 0,980 & 0,980 & 0,980 & 0,980 \\
\hline
\end{tabular}

1-Níveis de garantia para premix mineral -Vacinar - Composição por quilo do produto: Se 360 mg; I 1.400 mg; Fe 9.600 mg; Cu 20.000 mg; Mn 156.000; Zn 110.000 mg.

2-Níveis de garantia para premix vitamínico - Composição por quilo do produto: Vitamina A 30.000 .000 UI; Vitamina $D_{3}$ 6.000.000 UI; Vitamina E 60.000 mg; Vitamina $K_{3} 8.000$ mg; Vitamina $B_{1} 6.000$ mg; Vitamina $B_{2} 12.000 \mathrm{mg}$; Vitamina $B_{6} 12.000 \mathrm{mg}$; Vitamina $B_{12} 60.000$ ìg; Vitamina $C 100.000$ mg; Ácido fólico 3.000 mg; Ácido pantotênico 30.000 mg; Biotina $240 \mathrm{mg}$; Niacina $80.000 \mathrm{mg}$.

3 - Promotor de crescimento, 5g; 4 - Anticoccidiano, 5g.

O programa alimentar adotado constou de duas fases (1 a 21 dias e 22 a 42 dias). Os resultados foram submetidos à análise de variância utilizando-se o pacote computacional SISVAR 4.1, descrito por Ferreira (2000), realizando-se as análises de regressão linear e Linear Response Plateau (LRP) (BRAGA, 1983). 
TABELA 2 - Composição das rações utilizadas na fase final (22 a 42 dias) no experimento 2.

\begin{tabular}{|c|c|c|c|c|c|}
\hline \multirow{2}{*}{ Ingredientes } & \multicolumn{5}{|c|}{ Resíduo de Própolis (\%) } \\
\hline & Basal & 3 & 6 & 9 & 12 \\
\hline Milho & 62,96 & 59,77 & 53,99 & 47,77 & 42,09 \\
\hline Farelo de soja & 32,83 & 33,23 & 34,38 & 35,54 & 36,69 \\
\hline Óleo de soja & 1,00 & 0,87 & 2,54 & 4,03 & 5,61 \\
\hline Resíduo própolis & --- & 3,00 & 6,00 & 9,00 & 12,00 \\
\hline Fosfato bicálcico & 1,54 & 1,49 & 1,44 & 1,38 & 1,33 \\
\hline Calcário & 0,88 & 0,92 & 0,92 & 0,92 & 0,92 \\
\hline Sal & 0,38 & 0,37 & 0,38 & 0,38 & 0,38 \\
\hline Colina & 0,07 & 0,07 & 0,07 & 0,07 & 0,07 \\
\hline DL-metionina & 0,14 & 0,08 & 0,08 & 0,08 & 0,08 \\
\hline Suplemento mineral ${ }^{1}$ & 0,05 & 0,05 & 0,05 & 0,05 & 0,05 \\
\hline Suplemento vitamínico $^{2}$ & 0,05 & 0,05 & 0,05 & 0,05 & 0,05 \\
\hline Avilamicina ${ }^{3}$ & 0,05 & 0,05 & 0,05 & 0,05 & 0,05 \\
\hline Salinomicina $^{4}$ & 0,05 & 0,05 & 0,05 & 0,05 & 0,05 \\
\hline TOTAL & 100,00 & 100,00 & 100,00 & 100,00 & 100,00 \\
\hline \multicolumn{6}{|c|}{ Composição Nutritiva } \\
\hline $\mathrm{EM}(\mathrm{Kcal} / \mathrm{kg})$ & 3.000 & 3.000 & 3.000 & 3.000 & 3.000 \\
\hline Proteína bruta (\%) & 18,70 & 18,70 & 18,70 & 18,70 & 18,70 \\
\hline Metionina+cistina (\%) & 0,730 & 0,730 & 0,730 & 0,730 & 0,730 \\
\hline Lisina $(\%)$ & 1,11 & 1,11 & 1,11 & 1,11 & 1,11 \\
\hline Fósforo Disponível (\%) & 0,400 & 0,400 & 0,400 & 0,400 & 0,400 \\
\hline Cálcio (\%) & 0,860 & 0,860 & 0,860 & 0,860 & 0,860 \\
\hline
\end{tabular}

1-Níveis de garantia para premix mineral -Vacinar - Composição por quilo do produto: Se 360 mg; I 1.400 mg; Fe 9.600 mg; Cu 20.000 mg; Mn 156.000; Zn 110.000 mg.

2-Níveis de garantia para premix vitamínico - Composição por quilo do produto: Vitamina A 30.000.000 UI; Vitamina $D_{3}$ 6.000.000 UI; Vitamina E $60.000 \mathrm{mg}$; Vitamina $K_{3} 8.000 \mathrm{mg}$; Vitamina $B_{1} 6.000 \mathrm{mg}$; Vitamina $B_{2} 12.000 \mathrm{mg}$; Vitamina $B_{6} 12.000 \mathrm{mg}$; Vitamina $B_{12} 60.000$ ìg; Vitamina $C$ 100.000 mg; Ácido fólico 3.000 mg; Ácido pantotênico $30.000 \mathrm{mg}$; Biotina $240 \mathrm{mg}$; Niacina $80.000 \mathrm{mg}$.

3 - Promotor de crescimento, 5g; 4 - Anticoccidiano, 5g. 
As variáveis avaliadas foram: consumo de ração, ganho de peso e conversão alimentar.

\section{RESULTADOS E DISCUSSÃO}

\section{Avaliação do valor energético do resíduo da própolis}

O valor de energia bruta determinada no resíduo da extração da própolis foi $5718 \mathrm{Kcal} / \mathrm{kg}$. Esse alto valor de energia bruta se deve ao elevado teor de extrato etéreo presente no resíduo, e que, provavelmente, é composto de grande quantidade de ceras e óleos voláteis. Apesar do alto valor de energia bruta, apenas foram aproveitados no metabolismo dos galos $941 \mathrm{Kcal}$ de EM/kg de MS. Resende (1999) encontrou valores de energia metabolizável aparente corrigida de $2710 \mathrm{Kcal} / \mathrm{kg}$ de MS, com um nível de substituição de $10 \%$ na ração referência. Esse valor de energia encontrado foi aproximadamente 3 vezes maior que o encontrado no trabalho vigente, quando utilizaram galos adultos. O nível de resíduo utilizado neste ensaio de metabolismo foi de $20 \%$, que pode ter representado valores mais confiáveis de acordo com a metodologia de Matterson et al. (1965). Foi considerada na formulação das rações a energia determinada com os galos $941 \mathrm{Kcal}$ de EM/kg de MS.

\section{Avaliação do desempenho \\ Consumo de ração}

Verificou-se que não houve efeito significativo dos níveis de resíduo de própolis utilizados na ração e nem interação níveis x sexos sobre o consumo de ração $(P>0,05)$. No entanto, houve efeito de sexo $(\mathrm{P}<0,01)$ até 21 dias de idade. Os machos apresentaram consumo de ração $4,5 \%$ superior em relação às fêmeas. Pucci (2001) verificou que o consumo de ração apresentou comportamento linear crescente com a adição de níveis crescentes de óleo nas rações. Quando se aumentou a inclusão do resíduo da própolis nas rações, aumentaram-se também os níveis de óleo para que as rações fossem todas isoenergéticas. Esse aumento nos níveis de óleo provavelmente contribuiu na melhoria da palatabilidade das rações, minimizou as perdas de nutrientes, proporcionou maior efeito extra calórico e, conseqüentemente, propiciou maior consumo de ração, o que pode ter ocorrido neste experimento.
Na fase de 1 a 42 dias de idade houve efeito significativo de tratamento sobre sexos $(\mathrm{P}<0,01)$ e interação entre níveis $\mathrm{x}$ sexos $(\mathrm{P}<0,05)$, porém, não houve efeito dos níveis de inclusão do resíduo de própolis $(\mathrm{P}>0,05)$. Com relação aos sexos, somente houve efeito para os machos $(\mathrm{P}>0,05)$, com consumo máximo de $4,93 \%$, obtido pela equação Linear Response Plateau (LRP), com melhor ajustamento dos dados (Figura1).

\section{Ganho de peso}

De acordo com os resultados obtidos, verifica-se que houve diferença significativa no ganho de peso entre os níveis e entre sexos $(\mathrm{P}<0,01)$; no entanto, não houve interação entre níveis $x$ sexos $(\mathrm{P}>0,05)$ para as duas fases estudadas. Nas Figuras 2 e 3 estão ilustradas as equações de regressão para ganho de peso, para ambos os sexos, nas duas fases.

De acordo com os resultados obtidos na fase de 1 a 21 dias, observou-se que houve manutenção do peso até o nível de inclusão do resíduo na ração de $2,86 \%$, de acordo com a equação que melhor se ajustou aos dados LRP (Figura 2). A partir deste nível, o ganho de peso piorou, o que também se verificou na fase de 1 a 42 dias, na qual a medida que se aumentou os níveis de inclusão do resíduo na ração, ocorreu redução no ganho de peso das aves. A melhor resposta para ganho de peso ocorreu com níveis baixos de inclusão do resíduo na primeira fase de criação, estando esses resultados de acordo com Resende (1999), que utilizou níveis de inclusão até $4 \%$ na ração e não verificou diferenças entre os tratamentos. Apesar de não ter ocorrido diferença significativa no consumo de ração, o ganho de peso piorou na fase de 1 a 42 dias $(\mathrm{P}<0,01)$ com o aumento dos níveis de resíduo na ração, provavelmente devido ao seu alto teor de ceras $(26,76 \%)$. Segundo Nunes (1995), as ceras são ácidos graxos de cadeia longa (25 a 30 carbonos), com características altamente hidrofóbicas, não sendo atacadas por enzimas animais. O elevado teor de fibra bruta $(14,41 \%)$ presente no resíduo da própolis pode ter provocado redução da digestibilidade e da disponibilidade dos nutrientes. Segundo Bedford (1995), teores altos de fibras presentes no alimento dificultam a digestão, impedindo que as enzimas digestivas cheguem até os nutrientes, o que diminui a disponibilidade e absorção dos aminoácidos.

De acordo com este experimento, o ganho de peso para os machos nos períodos de 1 a 21 e 1 a 42 dias foram, respectivamente, $9,9 \%$ e 1,8\% maiores em relação aos ob- 
tidos por Resende (1999). O aumento no consumo de ração nessa fase pode ser explicado pelo aumento crescente de óleo nas rações, o que também foi verificado por Pucci (2001).

\section{Conversão alimentar}

Com relação à conversão alimentar, não houve diferença significativa $(\mathrm{P}>0,05)$ para sexos; no entanto, houve diferença significativa para os níveis de resíduo $(\mathrm{P}<0,01)$ e para interação níveis $\mathrm{x}$ sexos $(\mathrm{P}<0,01)$ na fase de 1 a 21 dias (Figura 4 ). Na fase de 1 a 42 dias, houve efeito dos níveis de resíduo e dos sexos $(\mathrm{P}<0,01)$ e também interação entre níveis $x$ sexos $(P<0,05)$. Para ambos os sexos, a conversão alimentar apresentou comportamento linear crescente de acordo com a inclusão dos níveis do resíduo na ração.

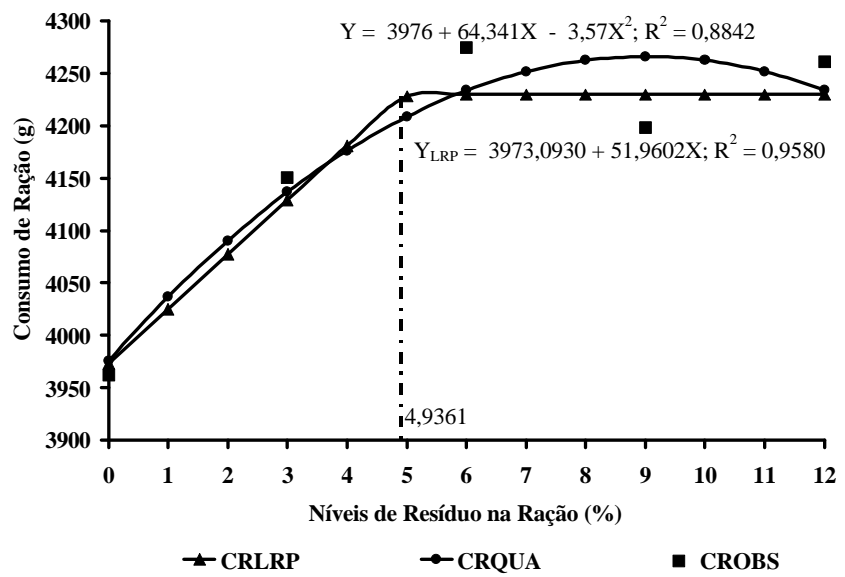

CRLP - Consumo de ração segundo LRP;

CRQUA - Consumo de ração segundo equação quadrática; CROBS - Consumo de ração observado.

FIGURA 1 - Consumo de ração de frangos de corte machos, de 1 a 42 dias, em função dos níveis de resíduo da própolis.

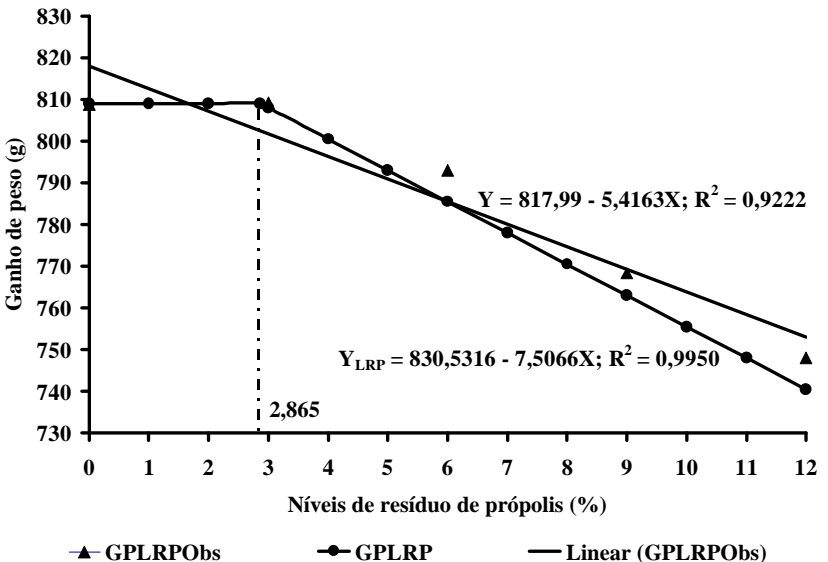

GPLRPObs - Ganho de peso segundo equação LRP observado; GPLRP - Ganho de peso segundo equação LRP;

GPLRP - Ganho de peso segundo equação linear LRP.

FIGURA 2 - Ganho de peso médio dos frangos de corte machos e fêmeas de 1 a 21 dias, em função dos níveis de resíduo de própolis na ração. 


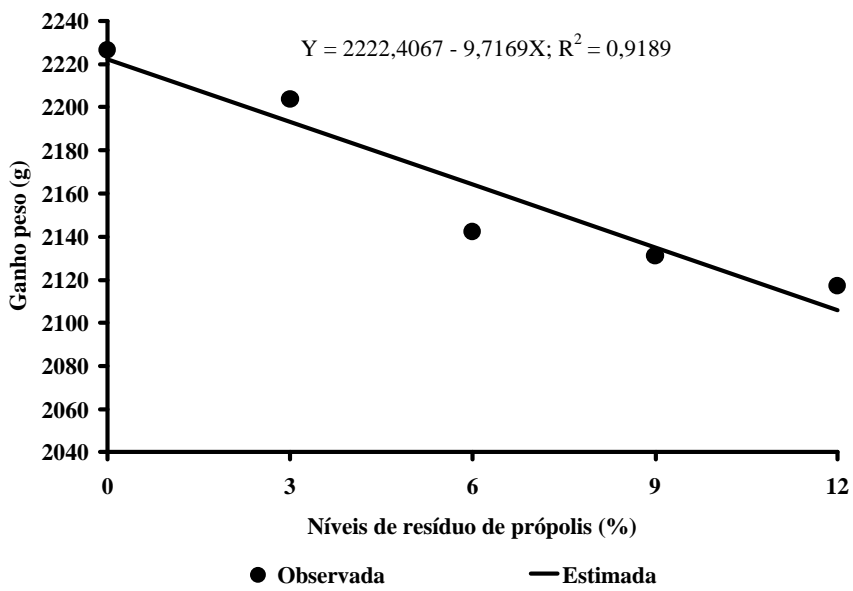

FIGURA 3 - Ganho de peso dos frangos machos e fêmeas de 1 a 42 dias, em função dos níveis de resíduo da própolis na ração.

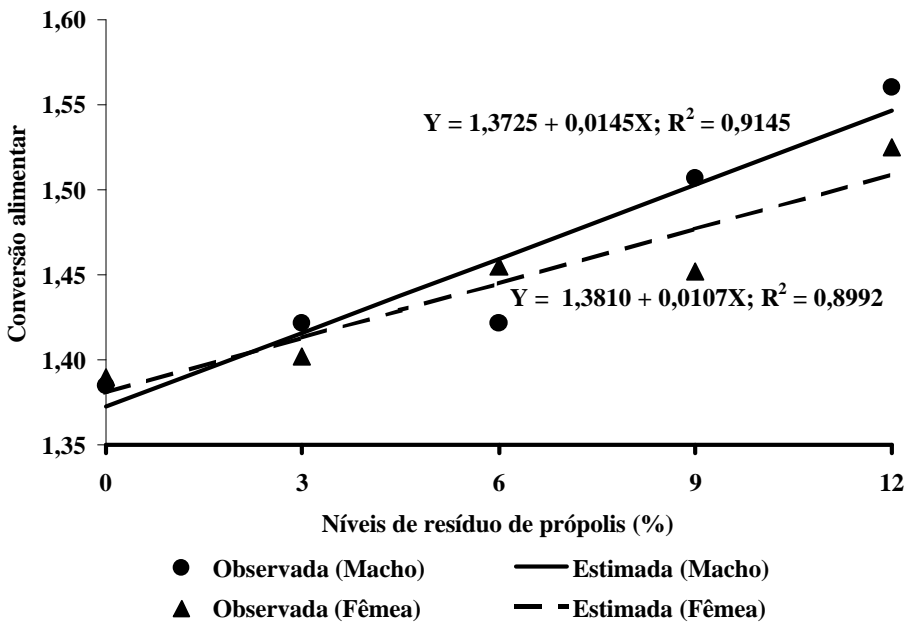

FIGURA 4 - Conversão alimentar dos frangos de 1 a 21 dias em função dos níveis de resíduo de própolis na ração.

\section{CONCLUSÕES}

a) A energia metabolizável aparente corrigida do resíduo da própolis para galos adultos é $941 \mathrm{Kcal}$ de $\mathrm{EM} / \mathrm{kg}$ de MS;

b) O resíduo da extração da própolis pode ser usado até $2,86 \%$ na dieta de frangos de corte, no período de 1 a 21 dias de idade;

c) A inclusão do resíduo da extração da própolis na dieta piorou o ganho de peso de frangos de corte na fase de 1 a 42 dias de idade.

\section{REFERÊNCIAS BIBLIOGRÁFICAS}

BEDFORD, M. R. Mechanism of action and potential environmental benefits from the use of feed enzymes. Animal Feed science Technology, Amsterdam, v. 53, n. 2, p. 145-155, June 1995.

BRAGA, J. M. Avaliação de fertilidade do solo: ensaios de campo. Viçosa: UFV, 1983. 101 p.

Ciênc. agrotec., Lavras. V.27, n.5, p.1152-1159, set./out., 2003 
FERREIRA, D. F. Sistema de análise estatística para dados balanceados (SISVAR). Lavras: UFLA/DEX, 2000 .

MARCUCCI, M. C. Propriedades biológicas e terapêuticas dos constituintes químicos da própolis. Química Nova, São Paulo, v. 19, n. 5, p. 529-534, set./out. 1996.

MATTERSON, L. D.; POTTER, L. M.; STUTZ, N. W.; SINGSEN, E. P. The metabolizable energy of feeds ingredient for chickens. Connecticut: The University of Connecticut-Agricultural Experiment Station, 1965. 11 p. (Research Peport, 7).

NUNES, I. J. Nutrição animal básica. Belo Horizonte: [s.n.], 1995. 334 p. Apostila.

PUCCI, L. E. A. Níveis de óleo e adição de complexo enzimático na ração de frangos de corte. 2001.46 p.
Dissertação (Mestrado em Zootecnia) - Universidade Federal de Lavras, Lavras, 2001.

RESENDE, I. R. Avaliação do resíduo da extração própolis para rações de frangos de corte. 1999. 40 p. Dissertação (Mestrado em Zootecnia) - Universidade Federal de Lavras, Lavras, 1999.

ROSTAGNO, H. S.; ALBINO, L. F. T.; DONZELE, J. L.; GOMES, P. C.; FERREIRA, R. S.; OLIVEIRA, R. F.; LOPES, D. C. Tabelas de composição de alimentos e exigências nutricionais de aves e suínos: tabelas brasileiras. Viçosa: UFV, 2000. 141 p.

SIBBALD, J. R.; SLINGER, S. J. A biological assay for metabolizable energy in poultry feed ingredientes together with findings which demonstrate some of the problems associated with the evaliation of fats. Poultry Science, Champaign, v. 42, n. 2, p. 313-325, Mar. 1963. 